\title{
Langmuir and Scatchard Parameters Do Not Describe the Binding of Actinomyces viscosus to Saliva-treated Hydroxyapatite
}

\author{
By BERNARD J. MONCLA, * LAUREL HALFPAP† AND \\ DALE C. BIRDSELL \\ Department of Oral Biology, School of Dentistry, University of Washington, Seattle, \\ WA 98195, USA
}

(Received 18 February 1985; revised 14 May 1985)

The binding of Actinomyces ciscosus T14V to saliva-treated spheroidal hydroxyapatite (SHA) beads was studied. The association constant $(K)$ and the total number of binding sites $(N)$ obtained from the Langmuir plots were in good agreement with those reported by other workers (approx. $3 \times 10^{-8}$ and $3 \times 10^{8}$, respectively). The values for $N$ obtained from Scatchard plots differed from those obtained from Langmuir plots by factors of $10^{6}$ or more. These results suggest that either these equations are inappropriate to describe binding or certain assumptions regarding this system are not being met. The use of these models requires, among other constraints, that the process be reversible and that measurements be taken at equilibrium. A method was developed which allowed a close examination of the equilibrium dynamics without perturbation of the system. The results suggest that the adsorption process is only poorly reversible. Adsorption to SHA was not at equilibrium after $1.5 \mathrm{~h}$. Even when bacteria were allowed to adsorb for longer periods, and the system appeared to approach equilibrium, the increased time of adherence did not significantly alter the derived $K$ or $N$ values. Our results suggest that the use of Scatchard and Langmuir plots is inappropriate to describe binding of A. viscosus to SHA.

\section{INTRODUCTION}

The adherence of the oral microbiota to the tooth surface is an important step in colonization (Gibbons \& van Houte, 1980; Myerthall \& Thomas, 1983). Because the tooth enamel is normally coated with a salivary pellicle, saliva-treated hydroxyapatite (SHA) beads have been widely used as an in vitro model system to study the adherence of the oral flora. Although several cell surface structures have been implicated in adherence to SHA (Brecher et al., 1978; Morris \& McBride, 1984; Wheeler \& Clark, 1980), the exact mechanisms involved in adherence are as yet undefined.

The adsorption model of Langmuir was first adapted to a bacterial system by Gibbons $\mathrm{et}$ al. (1976) and has been used extensively (Appelbaum et al., 1979; Clark et al., 1978, 1984; Morris \& McBride, 1984; Nesbitt et al., 1982). The model, which is based on equilibrium dynamics, has four constraints: (1) there is a finite number of identical binding sites per unit area of adsorbent; (2) the bacteria approach without steric hindrance; (3) the adsorption process is reversible up to and at equilibrium; and (4) measurements must be taken at equilibrium. The model can yield important information such as the number of binding sites $(N)$ and the association constants $(K)$ (Gibbons et al., 1976). A mathematically equivalent form of the Langmuir equation is the Scatchard equation (Dalquist, 1978; Nesbitt et al., 1982). More recently, Scatchard analysis has

$\uparrow$ Present address: ZymoGenetics, Seattle, WA, USA.

Abbreriations: HA, hydroxyapatite: SHA, saliva-treated hydroxyapatite: IAP. initial adsorption period: SADP, secondary adsorption/desorption period. 
also been used extensively for the study of bacterial adherence systems (Gibbons et al., 1983; Morris \& McBride, 1984; Nesbitt et al., 1982). If used under appropriate conditions, interpretation of these equations by graphical means should generate comparable values for the derived constants (Dalquist, 1978); therefore, a comparison of the values derived by the different methods would be a valuable check on the validity of the model.

It has been proposed that Gram-negative anaerobes initially colonize by association with supragingival plaque (Page \& Schroeder, 1982). A model system using Actinomyces viscosuscoated hydroxyapatite beads (Actinobeads) is being developed to investigate the interactions between Gram-negative anaerobic organisms and supragingival plaque. Before the Actinobeads system can be used the mechanisms of $\boldsymbol{A}$. viscosus adherence, including examination of kinetic parameters, need to be understood. The studies reported here were designed to examine the validity of the models, including critical examination of the equilibrium between adsorption and desorption.

\section{METHODS}

Organisms and culture conditions. A. viscosus strains T14V and T14AV were stored as multiple frozen stocks at $-70{ }^{\circ} \mathrm{C}$ in Trypticase soy broth (Difco) supplemented with $0.1 \%$ yeast extract and $0.5 \%$ glucose (TSBS) containing $20 \%(\mathrm{v} / \mathrm{v})$ glycerol. Tritium-labelled cells were prepared fresh from frozen stocks by growing the organisms for $16 \mathrm{~h}$ in TSBS containing either $10 \mu \mathrm{Ci}$ or $40 \mu \mathrm{Ci}\left[\right.$ methyl- ${ }^{3} \mathrm{H}$ ]thymidine $\mathrm{ml}^{-1}\left[20 \mathrm{Ci} \mathrm{mmol}^{-1}\right.$ $\left(740 \mathrm{GBq} \mathrm{mmol}^{-1}\right)$ : Amersham]. Organisms were collected by centrifugation at $10000 \mathrm{~g}$ for $10 \mathrm{~min}$, washed twice and suspended to the appropriate concentration in buffered $\mathrm{KCl}\left(0.05 \mathrm{M}-\mathrm{KCl}, 1 \mathrm{mM}-\mathrm{CaCl}_{2}, 0 \cdot 1 \mathrm{mM}-\mathrm{MgCl}_{2}, 0.02 \%\right.$ $\mathrm{NaN}_{3}$ containing $1 \mathrm{~mm}$-potassium phosphate, $\mathrm{pH} 7 \cdot 2$ ). Before dilution to the appropriate concentration, cell suspensions were dispersed by low power $30 \mathrm{~s}$ pulses from a micro-ultrasonic cell disrupter (Kontes, Vineland, $\mathrm{NJ}$, USA). Dispersal was effected on ice with three pulses, a $30 \mathrm{~s}$ cooling period being used after each sonic pulse. Following sonication, cells were observed microscopically to ensure that they were not present in large aggregates (greater than two). Preliminary work demonstrated that such treatment did not result in cell lysis. Other workers have demonstrated that much higher sonic energy levels are needed to remove the surface binding moieties of this organism (Wheeler \& Clark, 1980).

Salica preparation. Whole paraffin-stimulated saliva was collected on ice, clarified by centrifugation, heat inactivated and reclarified as previously described (Wheeler et al., 1979). The final preparation was brought to a concentration of $0.04 \%$ sodium azide and stored at $-30{ }^{\circ} \mathrm{C}$ until used. Occasionally a small amount of precipitate was formed after the saliva was thawed; this was removed by centrifugation at $10000 \mathrm{~g}$ for $10 \mathrm{~min}$ before use.

Bacterial adsorption to hydroxyapatite. Hydroxyapatite (HA) beads (40 mg; BDH) were placed in $1.65 \mathrm{ml}$ Eppendorf plastic centrifuge tubes, filled with $\mathrm{KCl}$ buffer. The tubes were closed and mixed by inversion at a rate of 12 per min. After $2 \mathrm{~h}$ the HA beads were allowed to settle for at least $1 \mathrm{~min}$ and the buffer was decanted. The beads were then washed twice with $\mathrm{KCl}$ buffer, $1.65 \mathrm{ml}$ of either clarified saliva or fresh $\mathrm{KCl}$ buffer was added and the tubes were mixed by inversion overnight. Immediately before use, beads were washed three times with $\mathrm{KCl}$ buffer. A $1.65 \mathrm{ml}$ volume of bacterial suspension was then added and the tubes were mixed by inversion for $1.5 \mathrm{~h}$. Bacterial adherence was determined by sampling $100 \mu \mathrm{l}$ from the supernatants and counting in $5 \mathrm{ml}$ Biofluor Scintillation Cocktail (Boston, Mass., USA) in a Packard Tricarb Scintillation spectrometer. In all experiments bacterial concentrations were determined by measuring the optical density in a Klett-Summerson photoelectric colorimeter and reading against a standard curve for concentration (determined by direct microscopic count). The specific radioactivity of the test organisms was determined for each experiment. The number of bacteria bound was calculated from differences in the radioactivity of the bacterial suspension before and after adherence. Two tubes were run for each bacterial concentration, each tube was sampled twice and all values were corrected for non-specific binding to the plastic tubes. Therefore, each point represented a mean of four samples and the variation was less than $5 \%$ in all cases. All the experiments reported were repeated at least three times.

Experiments to establish equilibrium. The experiments were done in two phases. During the first phase (initial adsorption period; IAP) cells were allowed to adsorb to SHA for varying periods of time. The IAP is equivalent to the adherence assay described above except that the time period in which the bacteria adsorbed was varied. Samples were taken at the end of the IAP for determination of the number of free and bound cells. The question of whether or not the system was at equilibrium when adherence samples were taken (i.e. at the end of the IAP) was investigated during the second phase of the experiment (secondary adsorption/desorption period; SADP). It was during the SADP that the dynamics of the adsorption/desorption process could be measured.

Two tubes of SHA were prepared. Radiolabelled bacteria were added to tube A at a given concentration. Unlabelled bacteria at the same concentration were added to tube $B$. The tubes were mixed by inversion for $1.5-$ $6.0 \mathrm{~h}$ (IAP). At the end of the IAP, samples were taken from the tube A supernatant to determine the number of 
free and bound bacteria. In the second phase the supernatants from each tube were decanted and saved. The supernatant from tube $\mathrm{A}$ (which contained radiolabelled free bacteria) was added to tube $\mathrm{B}$ (which contained SHA beads coated with unlabelled bacteria). Concurrently tube A and supernatant B were manipulated (see below) and the tubes were mixed for $1.5 \mathrm{~h}$ (SADP). At the end of the SADP, samples were taken from tube B and the number of cells adsorbed was determined. Tube A (which contained SHA coated with labelled bacteria) was prepared for the SADP by adding the supernatant from tube B (unlabelled free bacteria, taken after the IAP). At the end of the SADP, samples were taken from the supernatant and radioactivity was determined. This radioactivity represented the number of radiolabelled bacteria that had adsorbed during the IAP and were desorbed during the SADP

Experimental details. A. viscosus $\mathrm{T} 14 \mathrm{~V}$ was labelled with $\left[{ }^{3} \mathrm{H}\right]$ thymidine $\left(40 \mu \mathrm{Ci} \mathrm{ml} l^{-1}\right)$ and prepared as described above. Two concentrations were used, $1 \times 10^{\circ} \mathrm{ml}^{-1}$ and $5 \times 10^{-} \mathrm{ml}^{-1}$. For simplicity, the equilibrium experiment will be described with only one concentration but both concentrations were used in each experiment. Ten SHA tubes were prepared as described above: five tubes received $1.65 \mathrm{ml}$ of a suspension of radiolabelled bacteria at a concentration of $1 \times 10^{6} \mathrm{ml}^{-1}$, and five tubes received $1.65 \mathrm{ml}$ of a suspension of unlabelled bacteria at a concentration of $1 \times 10^{6} \mathrm{ml}^{-1}$. After various periods of mixing, samples were taken from tubes containing labelled bacteria to determine the number of bacteria bound $(2 \times 100 \mu 1 \mathrm{samples}$ from each tube). The nonadherent bacteria (i.e. those in the supernatant) were pooled from each set of tubes. Samples were taken from the pool of radiolabelled bacteria to determine the number of free bacteria. Extra tubes were included as insurance against wetting volume losses. Five tubes contained SHA which had radiolabelled organisms bound (A-tubes) and five tubes contained SHA with unlabelled organisms bound (B-tubes). A $1.65 \mathrm{ml}$ volume of the unlabelled organisms (from the pooled supernatants) was added to the A-tubes, two tubes were taken, mixed by inversion three times, allowed to settle for $1 \mathrm{~min}$ and $3 \times 100 \mu \mathrm{ls}$ samples were taken from each tube. These results were used to determine the number of bacteria trapped by the HA beads at zero time. After sampling, the tubes were centrifuged for $3.5 \mathrm{~min}$ in a Beckman microfuge and resampled. These values (non-sedimentable bacterial counts) were assumed to represent cell lysis. A $1.65 \mathrm{ml}$ volume of the radiolabelled organisms (from the pooled supernatant) was added to the B-tubes and all tubes were mixed for $1.5 \mathrm{~h}$. Samples were taken from the supernatants in triplicate and the contribution of lysed cells was determined as described above.

\section{RESULTS}

Preliminary studies demonstrated that neither the proportion of adsorbed bacteria nor the adherence kinetics were different when the HA was treated with saliva for $30 \mathrm{~min}$ or for up to $24 \mathrm{~h}$; therefore, for convenience, overnight treatments were used in all experiments.

The adherence of strain T14V to both HA and SHA was greater than that of strain T14AV (Table 1). This was particularly true at high cell concentrations $\left(6.6 \times 10^{7}\right.$ bacteria added per $40 \mathrm{mg}$ SHA). Although treating the HA with saliva promoted the adherence of strain T14V, such treatment inhibited the binding of strain T14AV. These data are consistent with those reported by other workers (Wheeler et al., 1979).

The adherence data were used to generate Langmuir, Scatchard and Hill plots. The binding parameters $N$ and $K$ were generated from a linear regression of the Langmuir isotherm. The values for $K$ and $N$ obtained for strain T14V to SHA and HA were comparable (Table 2). The $K$ and $N$ values obtained for strain TI4AV to SHA had a low coefficient of correlation $(0 \cdot 197)$ and are not interpreted. The association constant for the adherence of strain T14AV to HA $(0.05 \times$ $\left.10^{-8}\right)$ was lower than that observed for T14V $\left(2.61 \times 10^{-8}\right)$ and the number of binding sites $(N)$ was about one-quarter.

Scatchard plots have been used to demonstrate cooperativity in numerous binding systems (Dalquist, 1978; McGhee \& von Hippel, 1974), with the presence of a well-defined maximum being indicative of positive cooperativity (Dalquist, 1978; Edsall \& Gutfreund, 1983). The binding of strain T14V to both HA and SHA, when presented by the method of Scatchard appeared to be cooperative (Fig. 1). The binding of strain T14AV to HA and SHA resulted in markedly different binding curves (Fig. 1). Hill coefficients are the most reliable method to determine cooperative binding (Dalquist, 1978); accordingly, the binding data were used to generate Hill coefficients $\left(n_{\mathrm{H}}\right)$. All $n_{\mathrm{H}}$ values were less than or equal to 1 (Table 2), indicating that positive cooperativity is probably not involved in the binding of these systems (Dalquist, 1978; Edsall \& Gutfreund, 1983). When $N$ and $K$ values were generated from extrapolation of the downward slope of the Scatchard plots, the association constants (derived from the slope of the line) were comparable to those observed from the Langmuir isotherm (approx. $4 \times 10^{-8}$ ); 
Table 1. Adherence of A. viscosus strains T14V and T14AV to hydroxyapatite $(H A)$ and saliva-treated hydroxyapatite $(S H A)$ after $1.5 \mathrm{~h}$ incubation

\begin{tabular}{|c|c|c|c|c|}
\hline \multirow{2}{*}{$\begin{array}{c}10^{-7} \times \text { No. of } \\
\text { bacteria per } 40 \mathrm{mg} \\
\text { HA or SHA }\end{array}$} & \multicolumn{2}{|c|}{$\begin{array}{c}\begin{array}{c}\text { Percentage of } \\
\text { strain T14V } \\
\text { bound to: }\end{array}\end{array}$} & \multicolumn{2}{|c|}{$\begin{array}{c}\text { Percentage of } \\
\text { strain } \mathrm{T} 14 \mathrm{AV} \\
\text { bound to: }\end{array}$} \\
\hline & $\mathrm{HA}$ & SHA & $\mathrm{HA}$ & SHA \\
\hline 0.0825 & 80 & 85 & 75 & 0 \\
\hline $0 \cdot 165$ & 82 & 88 & 81 & 54 \\
\hline 0.825 & 90 & 92 & 73 & 48 \\
\hline 1.65 & 92 & 93 & 82 & 47 \\
\hline $3 \cdot 30$ & 88 & 93 & 80 & 47 \\
\hline $6 \cdot 60$ & 86 & 93 & 78 & 45 \\
\hline 9.9 & 70 & 90 & 61 & 40 \\
\hline 16.5 & 55 & 85 & 29 & 31 \\
\hline 82.5 & 23 & 37 & 1 & I \\
\hline
\end{tabular}

Table 2. Association constants $(K)$, total number of binding sites $(N)$ and Hill coefficients $\left(n_{H}\right)$ for binding of $A$. viscosus to $H A$ beads

$\begin{array}{cccccc}\text { Strain } & \begin{array}{c}\text { Hydroxyapatite } \\ \text { treatment* }\end{array} & \begin{array}{c}\text { Correlation } \\ \text { coefficient }\end{array} & N \dagger & K & n_{\mathrm{H}^{+}} \\ \text {T14V } & \text { Saliva } & 0.997 & 3.27 \times 10^{8} & 3.31 \times 10^{-8} & 0.76 \\ & \text { Buffer } & 0.994 & 1.93 \times 10^{8} & 2.61 \times 10^{-8} & 0.66 \\ \text { T14AV } & \text { Saliva } & 0.197 & 1.00 \times 10^{8} & 0.10 \times 10^{-8} & 1.00 \\ & \text { Buffer } & 0.981 & 0.58 \times 10^{8} & 0.05 \times 10^{-8} & 0.75\end{array}$

* Adherence was measured after $1.5 \mathrm{~h}$ of mixing.

$\dagger$ Total number of sites on $40 \mathrm{mg}$ HA beads.

$\ddagger$ Hill coefficients greater than 1.0 indicate positive cooperativity and less than 1.0 indicate negative cooperativity.

however, the number of binding sites calculated was about $10^{15}-10^{16}$ (compared with $10^{8}$ deduced from the Langmuir equation; Table 3). Because the data used to generate these parameters were identical and the equations are mathematically equivalent, comparable results from either expression would have been expected, but this was not observed.

The discrepancy in the number of binding sites calculated from the two methods suggests that this system does not fit within the constraints of the adsorption model. When $A$. viscosus T14V was allowed to adhere to SHA for $1.5,4.5$ and $6.0 \mathrm{~h}$, the number of cells bound was $6.69 \times 10^{7}$, $7.32 \times 10^{7}$ and $7.42 \times 10^{7}$, respectively. These data were analysed by Student's $t$-test. The numbers bound at $1.5 \mathrm{~h}$ and $4.5 \mathrm{~h}$ were significantly different $(P<0.01)$; however, the difference between the numbers bound at $4.5 \mathrm{~h}$ and $6.0 \mathrm{~h}$ was not significant. These data indicate that equilibrium was not reached in $1.5 \mathrm{~h}$ as has been reported by others (Wheeler et al., 1979). Incubation for longer periods altered the shapes of the Scatchard plots (Fig. 2) but did not markedly affect the values obtained from the Langmuir plot (Table 3).

Equilibrium in a system is defined as the state in which no net change is observed. In our system equilibrium would be reached when the number of free bacteria adsorbing to SHA per unit time was equal to the number of bound bacteria desorbing per unit time. Whenever the system is perturbed a new equilibrium must be established. This made it difficult to study equilibrium, as adding more cells or washing the bacteria-coated SHA would alter the system and create a new 'equilibrium'.

We circumvented these problems by simultaneously using labelled and unlabelled cells for adherence to SHA. By simply exchanging the supernatants from SHA adsorbed with radiolabelled cells with supernatants from SHA adsorbed with unlabelled cells, equilibrium data could be obtained without dramatically perturbing the system. The number of bacteria bound to SHA during the initial adsorption period (IAP) increased with increasing time (up to $6 \mathrm{~h}$; Table 4). Statistical analysis (Student's $t$-test) of the data for the high input numbers of bacteria 


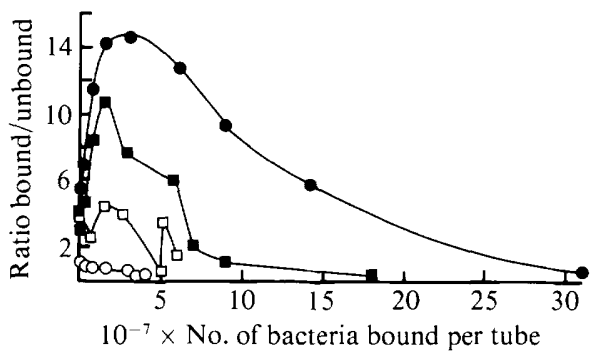

Fig. 1

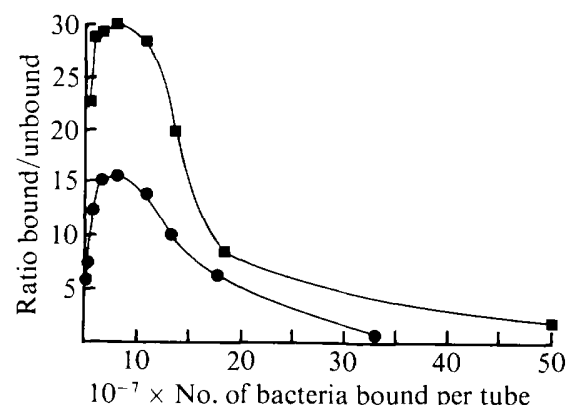

Fig. 2

Fig. 1. Scatchard plots for A. viscosus strains T14V (filled symbols) and T14AV (open symbols) binding to $40 \mathrm{mg}$ hydroxyapatite beads coated with either saliva $(\mathcal{O}, O)$ or buffer $(\boldsymbol{\square}, \square)$.

Fig. 2. Scatchard plots for the binding of A. viscosus $\mathrm{T} 14 \mathrm{~V}$ to saliva-treated hydroxyapatite beads. Bacteria were mixed for either $1.5 \mathrm{~h}(\mathbf{O})$ or $6.0 \mathrm{~h}(\square)$ before determination of the numbers bound.

Table 3. Association constants $(K)$ and total number of binding sites $(N)$ for binding of $A$. viscosus T14V to HA and SHA: effects of increased time of adherence and method of calculation

\begin{tabular}{|c|c|c|c|c|c|}
\hline \multirow{2}{*}{$\begin{array}{l}\text { Time } \\
\text { (h) }\end{array}$} & \multirow{2}{*}{$\begin{array}{l}\text { Type of } \\
\text { bead* }^{*}\end{array}$} & \multicolumn{3}{|c|}{ Langmuir } & \multirow{2}{*}{$\begin{array}{l}\text { Correlation } \\
\text { coefficient }\end{array}$} \\
\hline & & $\mathrm{N} \dagger$ & & $K$ & \\
\hline $1 \cdot 5$ & SHA & $3.27 \times 10^{8}$ & $3 \cdot 31$ & $\times 10^{-8}$ & 0.997 \\
\hline 1.5 & $\mathrm{HA}$ & $1.93 \times 10^{8}$ & $2 \cdot 61$ & $\times 10^{-8}$ & 0.994 \\
\hline $6 \cdot 0$ & SHA & $5.34 \times 10^{8}$ & 4.05 & $\times 10^{-8}$ & 0.995 \\
\hline $6 \cdot 0$ & $\mathrm{HA}$ & $4.12 \times 10^{8}$ & $2 \cdot 28$ & $\times 10^{-8}$ & 0.996 \\
\hline
\end{tabular}

$\overbrace{N^{\dagger}}^{\text {Scatchard }} \begin{array}{ccc}K & \begin{array}{c}\text { Correlation } \\ \text { coefficient }\end{array} \\ 6.36 \times 10^{15} & 4.73 \times 10^{-8} & 0.902 \\ 3.11 \times 10^{15} & 7.22 \times 10^{-8} & 0.958 \\ 1.06 \times 10^{15} & 1.83 \times 10^{-7} & 0.958 \\ 4.27 \times 10^{14} & 2.69 \times 10^{-7} & 0.987\end{array}$

* SHA, hydroxyapatite beads treated with saliva as described in Methods; HA, not saliva-treated.

† Total number of binding sites per $40 \mathrm{mg} \mathrm{HA}$ beads.

Table 4. Adsorption and desorption of A. viscosus T14V to SHA as a function of the length of the initial adsorption period

A. viscosus $\mathrm{T} 14 \mathrm{~V}$ were adhered to SHA for the indicated time before rate determinations were made (see text).

\begin{tabular}{lcclcc}
\multirow{2}{*}{ Input* } & Time $(\mathrm{h})$ & $\overbrace{\text { Bound } \dagger} 10^{-7} \times$ Free $_{+}$No. of bacteria & Adsorbing $\S$ & Desorbing $\|$ \\
High & 1.5 & 6.050 & 1.765 & 1.003 & 0.114 \\
& 4.5 & 6.985 & 0.618 & 0.285 & 0.113 \\
\multirow{3}{*}{ Low } & 6.5 & 7.190 & 0.538 & 0.273 & 0.084 \\
& 1.5 & 0.142 & 0.01116 & 0.0093 & 0.0008 \\
& 4.5 & 0.154 & 0.00265 & 0.0005 & 0.008 \\
& 6.5 & 0.147 & 0.0031 & 0.0007 & 0.0014
\end{tabular}

* High, $8.25 \times 10^{7}$ bacteria added per tube; low, $0.165 \times 10^{7}$ bacteria added per tube.

$\dagger$ Bacteria bound per $40 \mathrm{mg}$ SHA per tube during the indicated time.

$\ddagger$ Bacteria free per tube was determined from the number of bacteria in the pooled supernatants of nonadhered organisms.

$\S$ Number of organisms adsorbing to $40 \mathrm{mg}$ SHA during the secondary adsorption/desorption period. Data were calculated by difference and adjusted for the number of lysed bacteria (non-sedimentable c.p.m. are assumed to represent lysed organisms).

\| Number of bound organisms desorbed from SHA during the secondary adsorption/desorption period. 
demonstrated that the differences observed in the numbers of bacteria bound were significant at the $P<0.001$ level. At the lower input numbers of bacteria the numbers of bacteria bound at $1.5 \mathrm{~h}$ and $4.5 \mathrm{~h}$ were significantly different $(P<0.05)$ while no significant difference was observed between the numbers bound at $4.5 \mathrm{~h}$ and $6.0 \mathrm{~h}$. These data demonstrated that equilibrium was not reached after $1.5 \mathrm{~h}$ of adherence. This was confirmed by examination of the dynamics of the system during the $1.5 \mathrm{~h}$ which followed the IAP, referred to as the secondary adsorption/desorption period (SADP). With high input numbers of bacteria $\left(8.25 \times 10^{7}\right.$ bacteria per tube), the number of bound cells that were desorbed was relatively constant regardless of the IAP (i.e. $1 \cdot 5,4 \cdot 5$ or $6.0 \mathrm{~h})$. With low input numbers of bacteria $\left(0 \cdot 165 \times 10^{7}\right.$ per tube) the same trend was observed; however, the percentage of bound cells desorbed was approximately three- to fourfold greater than that observed at the higher input. The number of cells adsorbed during the SADP was approximately three- to fourfold greater when the IAP was $1.5 \mathrm{~h}$ than when it was 4.5 or $6.0 \mathrm{~h}$; this result was observed for both high and low input numbers of bacteria. With high input numbers of bacteria, after an IAP of $1.5 \mathrm{~h}$ the ratio of adsorbed to desorbed cells during SADP was approximately 9; this ratio dropped to about 3 after an IAP of 4.5 and $6.0 \mathrm{~h}$. The data for low input numbers demonstrated a similar trend with ratios of 12,2 and 2 , respectively, for the different periods. These results clearly demonstrated that the system was not at equilibrium when cells and SHA were mixed for $1.5 \mathrm{~h}$.

\section{DISCUSSION}

The adherence of Actinomyces viscosus to SHA and HA was studied as a function of cell concentration and time. The results demonstrated that saliva promoted the adherence of slightly greater numbers of strain T14V (as compared to HA) but the values obtained for $N$ and $K$ from these binding data were very similar. In contrast, saliva inhibited the binding of strain T14AV. The number of binding sites for T14AV was less than that observed for strain T14V. Although these results demonstrated the same general trend as has been reported by other workers, our values differed by a factor of 10 from those reported by Wheeler et al. (1979). Considering that some values reported by Clark in successive papers (Clark et al., 1978; Wheeler et al., 1979) differed by a factor of 10 or more, the values we report are comparable to those of Wheeler et al. (1979). In other systems it is known that different values are obtained when using different concentrations of bacteria (Appelbaum et al., 1979; Clark et al., 1978; Gibbons et al., 1983). Here we used a 10 -fold wider range of bacterial concentration than Wheeler et al. (1979). Strain T14V was shown to have a 30 -fold greater affinity for SHA than strain T14AV and was similar to certain other oral organisms in that saliva inhibited adherence to SHA (Nesbitt et al., 1982). The binding of $A$. viscosus to SHA appears to involve type 1 fibrils (Brecher et al., 1978; Clark et al., 1981, 1984; Wheeler \& Clark, 1980). Strain T14AV is an avirulent variant derived from strain T14V (Wheeler et al., 1979). Growth of strain T14AV in TSBS suppresses production of fibrillar antigens and enhances capsular antigen production (Gibbons et al., 1983; Ooshia \& Kuramitsu, 1981; Powell et al., 1978). The avirulent variant is unable to colonize the gingival crevice region of the tooth in germ-free rats (Brecher et al., 1978) and has a greatly reduced ability to adhere and colonize in the human mouth (Wheeler et al., 1979). The observation that strain T14AV binds to HA and SHA and the different binding parameters suggest that two distinct mechanisms of adherence are involved. However, such interpretations are much more meaningful if the system is described by the models.

Analysis of binding data by Langmuir, Scatchard and Hill plot methods can provide valuable information. It is important to demonstrate that the binding data are adequately described by such models before interpretation of such data. The observation that extrapolation of the $N$ value from Langmuir and Scatchard plots yields strikingly different results clearly demonstrates that these models do not adequately describe the binding of $A$. viscosus to SHA. This would suggest that one of the basic constraints of the binding model is not being met.

Analysis of the raw data obtained from the equilibrium experiments suggested that the organisms do desorb from SHA, i.e. the reaction is reversible, since between $5 \%$ and $10 \%$ of the bound organisms were desorbed. However, after adjustments for lysed bacteria were made, the 
number of bound organirms which desorbed was less than $2 \%$, indicating the reaction strongly favours binding. The contribution of mechanical abrasion in the system cannot be evaluated at present. Previous workers have reported that the adsorption process of $A$. viscosus to SHA reaches equilibrium after $30 \mathrm{~min}$ (Wheeler et al., 1979) and most workers have used an incubation period of $1.5 \mathrm{~h}$. The results reported here demonstrated that the adherence process had not reached equilibrium after $1.5 \mathrm{~h}$, as evidenced by the ratio of adsorbed to desorbed cells of about 10. After an initial adsorption period of $4.5 \mathrm{~h}$ or more, the system appeared to approach equilibrium (adsorption to desorption ratio was approximately 2 ). Whether this ratio was significantly different from a value of 1 (the ideal value expected at equilibrium) was difficult to determine from the available data. Increasing the time of adherence for the kinetic studies did alter the shapes of the curves and values derived for $N$ and $K$. However, these changes were not sufficient to explain the discrepancies as being the result of lack of equilibrium.

A. viscosus is known to grow in large aggregates which would suggest some cell-cell affinity. If such cell-cell affinities were involved in the adherence of this organism to HA or SHA, adherence could be viewed as a cooperative interaction. If a free organism were to bind to a cell which was already bound to SHA, the bound cell would represent a binding site that was distinct from the site on the SHA. In such a system the total number of SHA binding sites would remain constant, with the available SHA binding sites decreasing, while the total number of sites in the system would increase with increasing numbers of bound bacteria. Such a system would not be consistent with current models as there would not be a finite number of independent binding sites. Wheeler et al. (1979) observed that A. viscosus forms multiple layers on SHA and we have observed the same phenomenon at high concentrations $\left(5 \times 10^{7}\right.$ bacteria $\mathrm{ml}^{-1}$, unpublished observations). When the equilibrium experiments were done with high $\left(5 \times 10^{7} \mathrm{ml}^{-1}\right)$ and low $\left(1 \times 10^{6} \mathrm{ml}^{-1}\right)$ bacterial concentrations, each gave comparable results suggesting that cell-cell interaction was not an important consideration in these equilibrium experiments.

As stated above, the models discussed in this work have been used extensively in the study of other bacterial adherence systems and have been used to postulate mechanisms for the binding process. It must be stressed that mathematical models cannot provide information concerning mechanisms and their value lies in the fact that any proposed mechanisms and all observations must be consistent with the model (Edsall \& Gutfreund, 1983). The observation reported here demonstrates that binding of $A$. viscosus to SHA is not consistent with currently accepted models. New models consistent with the observations are needed to enhance our understanding of the adherence process.

This research was supported by National Institutes of Health grants DE 07023, DE 02600 and DE 05991. The authors wish to acknowledge the contributions of Luella Parsons in the preparation of this manuscript.

\section{REFERENCES}

Appelbalm, B., Golub, E., holt, S. C. \& Rosan, B. (1979). In vitro studies of dental plaque formation: adsorption of oral Streptococci to hydroxyapatite. Infection and Immunity 25, 717-728.

Brecher, S. M., van Houte, J. \& Hammond. B. F. (1978). Role of colonization in the virulence of Actinomices riscosus strain $\mathrm{Tl} 4 \mathrm{-Vi}$ and Tl4-AV. Infection and Immunity 22, 603-614.

Clark, W. B., Bammann, L. L. \& Gibbons, R. J. (1978). Comparative estimates of bacterial affinities and adsorption sites on hydroxyapatite surfaces. Infection and Immunity 19, 846-853.

Clark, W. B., Webr. E. L., Wheeler, T. T., Fischlschweiger, W., Birdsell, D. C. \& MaNSHEIM. B. J. (1981). Role of surface fimbriae (fibrils) in the adsorption of Actinomyces species to salivatreated hydroxyapatite surfaces. Infection and Immunity 33, 908917.

Clark, W. B., Wheeler, T. T. \& Cisar, J. O. (1984).
Specific inhibition of adsorption of Actinomyces riscosus T14V to saliva-treated hydroxyapatite by antibody against type 1 fimbriae. Infection and Immunit 43, 497-501.

DALQList, F. W. (1978). The meaning of Scatchard and Hill plots. Methods in Enzlmolog! 48, 270299.

Fdsall, J. T. \& Gutfreund, H. (1983). Biothermodynamics, the Study of Biochemical Processes at Equilihrium. New York: John Wiley \& Sons

Gibbons, R. J. \& van Houte, J. (1980). Bacterial adherence and the formation of dental plaque. In Bacterial Adherence, Receptors and Recognition, series B, vol. 6, pp. 62 104. Edited by E. H. Beachey. London: Chapman \& Hall.

Gibbons, R. J.. Moreno, E. C. \& Spinell, D. M. (1976). Model delineating the effects of a salivary pellicle on the adsorption of Streptococcus miteor onto hydroxyapatite. Infection and Immunity 14, $1109-1112$. 
Gibbons, R. J., Moreno, E. C. \& Etherden, I. (1983). Concentration-dependent multiple binding sites on saliva-treated hydroxyapatite for Streptococcus sanguis. Infection and Immunity 39, 280-289.

MCGheE, J. D. \& VON HIPPEL, P. H. (1974). Theoretical aspects of DNA protein interactions: cooperative and noncooperative binding of large ligands to a one-dimensional homogeneous lattice. Journal of Molecular Biology 86, 469-489.

MorRis, E. J. \& MCBridE, B. C. (1984). Adherence of Streptococcus sanguis to saliva-coated hydroxyapatite: evidence for two binding sites. Infection and Immunity 43, 656 663 .

Myerthall, D. L. \& Thomas, T. H. (1983). Kinetics of adherence of Actinomyces riscosus to saliva-coated silica and hydroxyapatite beads. Journal of General Microbiology' 129, 1387-1395.

Nesbitt, W. E., Doyle, R. J., Taylor, K. G., Staat, E. H. \& ARNold, R. R. (1982). Positive cooperativity in the binding of Streptococcus sanguis to hydroxyapatite. Infection and Immunity 35, 157-165.
Ooshima, T. \& Kuramitsu, H. K. (1981). Regulation of extracellular slime production by Actinomyces riscosus. Infection and Immunity 32, 1105-1112.

PAGE, R. C. \& Schroeder, H. H. (1982). Periodontitis in Man and Animals: A Comparative Review. New York: S. Karger Publishers.

Powell, J. T., Fischlschweiger, W. \& Birdsell, D. C. (1978). Modification of surface composition of Actinomyces viscosus $\mathrm{T} 14 \mathrm{~V}$ and $\mathrm{T} 14 \mathrm{AV}$. Infection and Immunity 22, 934-944.

WheEler, T. T. \& ClaRK, W. B. (1980). Fibrilmediated adherence of Actinomyces riscosus to saliva-treated hydroxyapatite. Infection and Immunity 28, 577-584

Wheeler, T. T., Clark, W. B. \& Birdsell, D. C. (1979). Adherence of Actonomvces viscosus TI4V and $\mathrm{Tl} 4 \mathrm{AV}$ to hydroxyapatite surfaces in vitro and human teeth in rivo. Infection and Immunity 25, 10661074. 